\title{
Distinctive Soft Tissue Tumors of the Head and Neck
}

\author{
Christopher D.M. Fletcher, M.D., F.R.C.Path. \\ Department of Pathology, Brigham \& Women's Hospital and Harvard Medical School, Boston, \\ Massachusetts
}

\begin{abstract}
Among soft tissue tumors as a whole, those in the head and neck region are relatively uncommon, and the proportion of all soft tissue sarcomas that arise in this region is $\mathbf{5} \mathbf{- 1 0 \%}$ (although this figure is higher in children). With the exceptions of nasopharyngeal angiofibroma and sinonasal hemangiopericytoma, most mesenchymal lesions are not truly distinctive to this site. This overview focuses on tumors that show a relative predilection for this region, including principally benign fibroblastic/myofibroblastic lesions, nerve sheath tumors, vascular tumors (both benign and malignant), and small round cell sarcomas, especially rhabdomyosarcoma in young patients. Important generalizations to bear in mind include the facts that (1) among spindle cell malignancies in the head and neck of adults, spindle cell carcinoma and melanoma are by far more common than sarcomas; (2) because of anatomic constraints and dramatic clinical presentation, the index of clinical suspicion for malignancy is often high; (3) certain subsets of benign mesenchymal lesions in this anatomic region frequently show pseudosarcomatous morphology; and (4) the ability to define or obtain an adequate surgical resection margin in this region is often very limited, hence issues of local control may supercede the importance of overall biologic/metastatic potential in some cases.
\end{abstract}

\section{KEY WORDS: Head, Neck, Sarcoma, Soft tissue.} Mod Pathol 2002;15(3):324-330

Among soft tissue tumors in general, those in the head and neck region are relatively uncommon, and the proportion of all soft tissue sarcomas that arise in this region is no more than 5-10\%, although the proportion is somewhat higher in children. Most of the mesenchymal lesions that arise in soft

Copyright (C) 2002 by The United States and Canadian Academy of Pathology, Inc.

VOL. 15, NO. 3, P. 324, 2002 Printed in the U.S.A.

Date of acceptance: September 27, 2001.

Address reprint requests to: Christopher D.M. Fletcher, M.D., F.R.C.Path Department of Pathology, Brigham and Women's Hospital, 75 Francis Street, Boston, MA 02115; e-mail: cfletcher@partners.org; fax: 617-566-3897. tissue of the head and neck are not truly distinctive to this site, with the notable (perhaps unique) exceptions of nasopharyngeal angiofibroma, and sinonasal hemangiopericytoma, but there are some tumors that show a relative predilection for this region, including cutaneous angiosarcoma, capillary hemangioma of juvenile/cellular type, atypical fibroxanthoma, pediatric rhabdomyosarcoma and perhaps solitary fibrous tumor. It is the purpose of this brief overview to focus on the more distinctive or more frequently encountered soft tissue lesions in this general anatomic region and to mention briefly aspects of lesions more often found at other locations that are of particular relevance when they occur in the head and neck.

\section{GENERAL OBSERVATIONS}

Before discussing these soft tissue lesions, it is important to appreciate some broad generalities that apply to the diagnosis and management of mesenchymal lesions (particularly spindle cell lesions) in the head and neck. Foremost, at least in the context of adult patients, is that nonmesenchymal lesions in this anatomic region very often have spindle cell morphology, most notably spindle cell (or sarcomatoid) squamous cell carcinoma and malignant melanoma of spindle cell or desmoplastic types. These lesions may present at cutaneous, mucosal, or deeper soft tissue locations or may mimic sarcoma in metastatic sites, particularly lymph nodes. When dealing with almost any cytologically malignant spindle cell lesion in this region, it is advisable to consider these lesions first in the differential diagnosis because squamous carcinomas and melanomas (including the sarcomatoid variants) are substantially more common than are primary sarcomas. Second, because of the complex anatomic constraints of this region, almost any space-occupying lesion (neoplastic or otherwise, benign or malignant) can raise serious clinical or radiologic concerns for malignancy (Fig. 1), either because of compression or erosion of adjacent structures or because of dramatic symptomatology (e.g., facial swelling, proptosis, etc.). Thus, the index 


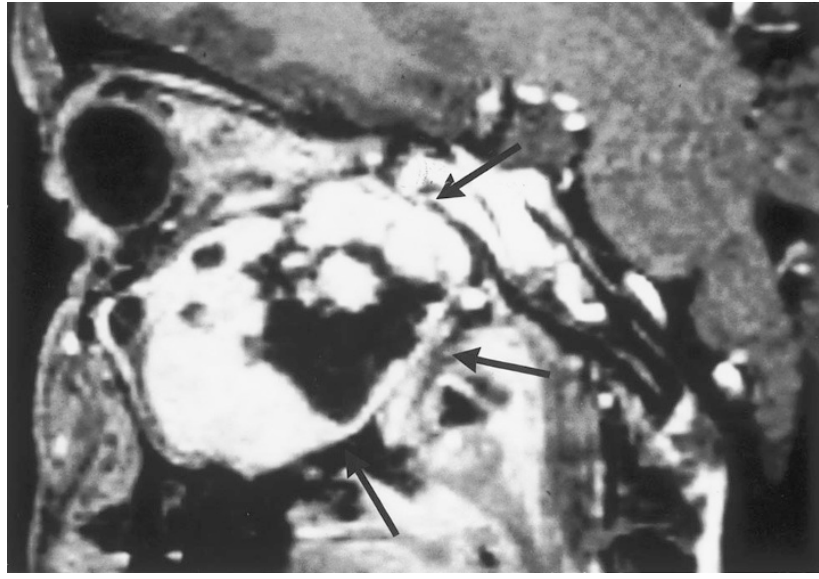

FIGURE 1. Schwannoma arising from the second division of the trigeminal nerve. Although essentially a biologically innocuous neoplasm, the clinicoradiologic presentation and pressure effects may be both dramatic and significant. (Courtesy of Dr. Ivo Janecka, Boston, MA.)

of clinical suspicion (and patient anxiety) is often high, and the dependence on accurate histologic diagnosis is often considerable. In this context, it is important also to be aware of the tendency of certain benign lesions to show histologically pseudomalignant features, such as reactive endothelial atypia in angiomatous lesions of the oral cavity, lip (1) and nose, the absence of encapsulation of benign schwannomas in the sinonasal tract, and the overtly sarcomatoid morphology of atypical fibroxanthoma.

These anatomical constraints, which arguably are more significant than at other soft tissue locations, have other important consequences. First, the relative inaccessibility of many head and neck locations (even with modern biopsy techniques) means that the diagnostic tissue biopsy is often very small and frequently shows crush artifact, making interpretation significantly more difficult. Although, theoretically, this issue can be addressed (at least partially) by using fine needle aspiration, at the present time the latter technique is more effective in primary diagnosis of epithelial rather than mesenchymal lesions, other than in experienced hands. Second, in the context of any locally aggressive lesion (irrespective of its metastatic potential), it is often impossible (or exceedingly difficult) to properly define or obtain adequate surgical resection margins in many head and neck sites. In addition, radiation therapy is not as effective in obtaining local control as it is for epithelial tumors at this location-thus, as with neoplasms of the central nervous system, the biologic potential of a given lesion (even if incapable of metastasis) may be more significant than at other more accessible and resectable sites, and there are major problems in identifying effective treatment to obtain local control at many head and neck locations.
With regard to the specific histologic subtypes of soft tissue sarcoma encountered in the head and neck region, the relative incidence is significantly influenced by patient age and anatomic location (2-4). In adults, the four commonest topographic groups are lesions in the neck (including larynx/ pharynx), in which liposarcoma (most often of well-differentiated type; 5, 6), malignant peripheral nerve sheath tumor (MPNST), and synovial sarcoma predominate; the skin of the scalp and face, where angiosarcoma and dermatofibrosarcoma protuberans are most frequent; the sinonasal tract, in which MPNST is commonest, followed by myxofibrosarcoma; and the oral cavity, in which leiomyosarcoma and rhabdomyosarcoma are most often encountered.

It is worth commenting that high-grade pleomorphic ("MFH"-like) sarcomas are very uncommon in this region, as also are myxoid/round cell liposarcomas, despite their considerable frequency in other sites such as the thigh. The majority of pleomorphic spindle cell malignancies in the head and neck are either sarcomatoid epithelial (or melanocytic) lesions, as mentioned above, or else are unclassified postradiation sarcomas, which are relatively more common in this anatomic region.

In children and adolescents, the picture is very different, and the vast majority of soft tissue malignancies are rhabdomyosarcomas, which are discussed in more detail below. Most of the soft tissue sarcomas mentioned above are not at all distinctive to this location and are not discussed further here.

It is important to note that, principally because of the site-specific anatomic constraints and therapeutic difficulties mentioned above, the major prognostic factors for soft tissue sarcomas in the head and neck region are resectability, tumor size (which also correlates with resectability), and tumor stage $(2,3)$. Histologic subtype, although one of the most important determinants of outcome at most other anatomic locations, has less impact in this anatomic region because the extent to which a tumor can be controlled locally has greater significance than risk of metastasis in the head and neck.

The majority of the soft tissue lesions, benign or malignant, that occur most often in the head and neck region can be subdivided into broad categories based on cell type, and it is under these headings that they are described below.

\section{FIBROBLASTIC/MYOFIBROBLASTIC LESIONS}

Nodular fasciitis is relatively common in the head and neck region, particularly in the forehead, cheek, and neck, although sites such as the oral cavity and orbit can also be affected. Children are relatively more often affected than at other sites, 
and in these patients, myxoid stroma may be more prominent. A subset of pediatric cases is associated with erosion of adjacent bone (parosteal/cranial fasciitis; 7,8 ), but this has no major clinical consequences. Desmoid fibromatosis in this region is also more common in children $(9,10)$ and shows a predilection for the lower jaw and neck. As elsewhere, these lesions may be very infiltrative and destructive. The major consequences of radical surgery, particularly for jaw lesions, have led to the frequent use of chemotherapy in pediatric cases (10). Solitary myofibroma and myofibromatosis are relatively frequent in the head and neck region, particularly in the oral cavity, tongue, and gingival/ jaw tissues. These lesions occur in both adults and children, are more often solitary rather than multifocal, and are generally nonaggressive. Inflammatory myofibroblastic tumor occurs in the sinonasal region, particularly in young patients, and shows the same clinicopathologic features as at more common intraabdominal locations (11).

Solitary fibrous tumor $(12,13)$ arises at a variety of sites in the head and neck region, notably in salivary glands, soft tissues of the cheek and mouth, the orbit, and in the sinonasal tract. Meningeal location is also well recognized. As at other locations, such lesions were often formerly labeled as hemangiopericytoma, and some in the orbit were also called fibrous histiocytoma. The histologic appearances are essentially no different than at other

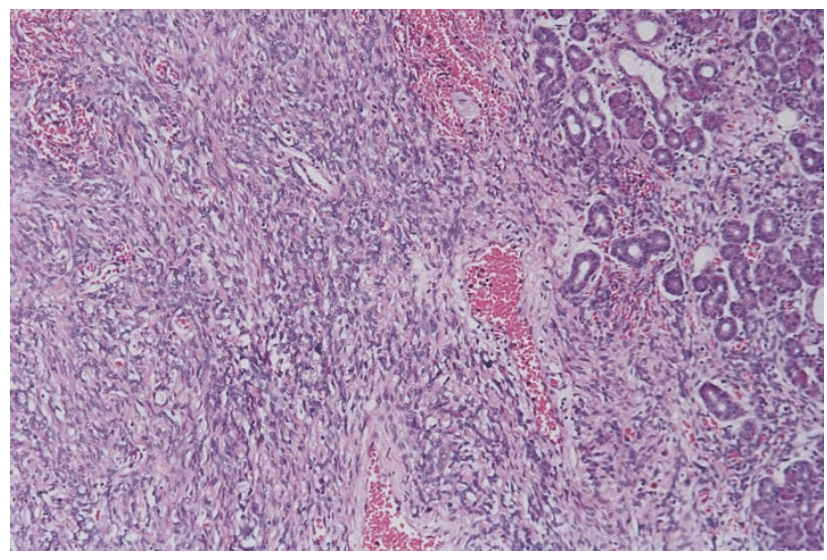

FIGURE 2. Solitary fibrous tumor involving submandibular gland. Note the patternless appearance and collagenous stroma.

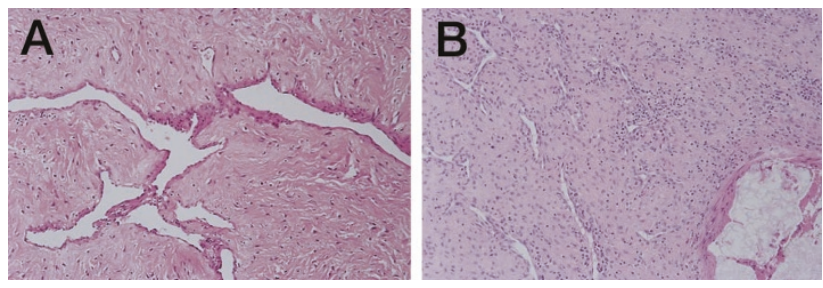

FIGURE 3. Nasopharyngeal angiofibroma. The more sclerotic lesion on the left (A) shows striking variation in vessel wall thickness. The more cellular example (B) shows thin-walled angulated vessels, as well as evidence of prior embolization (bottom right). sites, being characterized by a patternless architecture (Fig. 2), varying cellularity (often with areas of stromal hyalinization), and a frequently branching hemangiopericytoma-like vascular pattern. These tumors show fairly consistent immunopositivity for CD34, CD99, and bcl-2. Most cases occur in adults, and perhaps because of earlier presentation, the

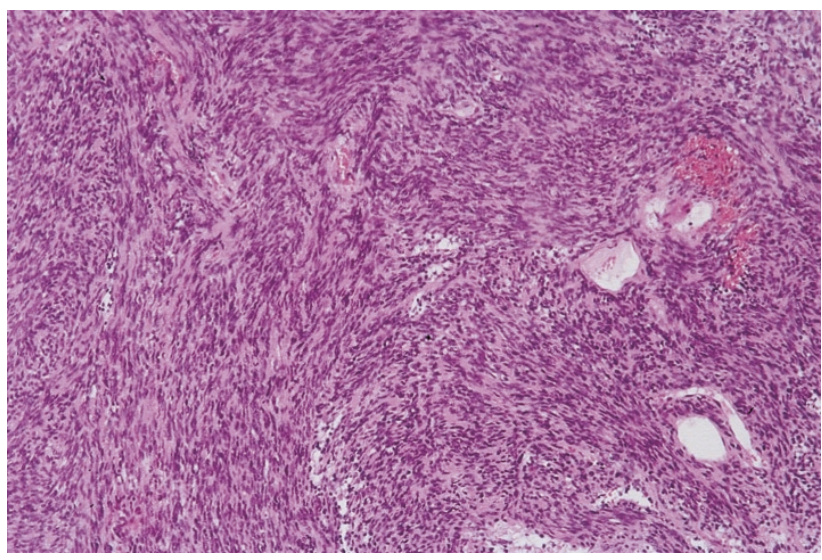

FIGURE 4. Cellular schwannoma from the nasal cavity. Careful distinction from malignant peripheral nerve sheath tumor or monophasic synovial sarcoma is important.

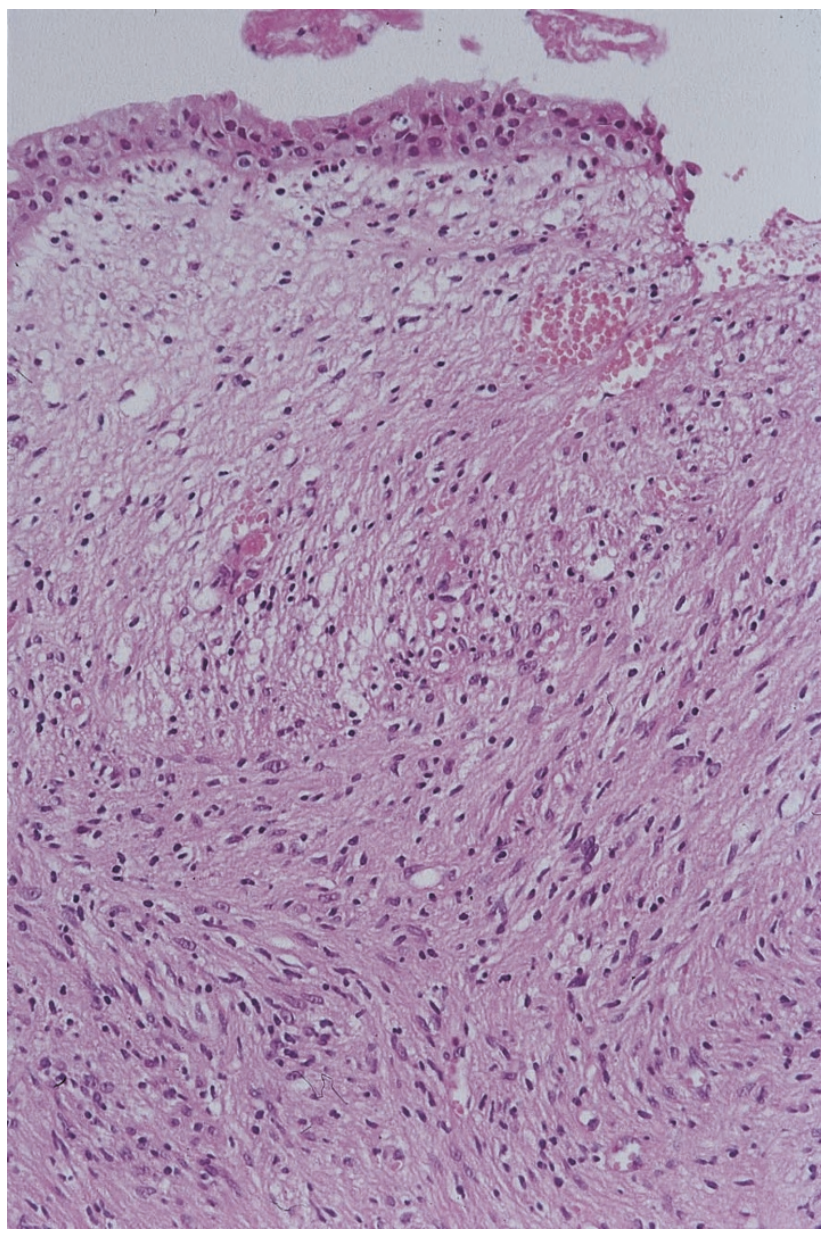

FIGURE 5. Schwannoma involving maxillary sinus. Note the absence of encapsulation, a distinctive feature of benign schwannomas in the upper respiratory tract and stomach. 
majority of lesions measure $<5 \mathrm{~cm}$ and pursue a benign clinical course. Criteria for malignancy are the same as at other locations (14).

Nasopharyngeal angiofibroma is a very well known but rare entity that occurs almost exclusively in males, particularly adolescents and young adults $(15,16)$. It generally originates in the roof of the nasal cavity, perhaps from erectile tissue normally present in that location, and is characterized by slow, locally destructive growth and a significant tendency for hemorrhage (spontaneous or intraoperative). These tumors may extend into the nasal cavity or skull base or, externally, into the cheek, giving rise to significant deformity. Depending on excision margins, there is a significant risk of local recurrence (particularly for lesions with intracranial extension), which has led sometimes to the use of radiotherapy. However, this is associated with development of sarcoma in some cases, and surgery (with or without embolization) is most often preferred nowadays. Interestingly, an association between nasopharyngeal angiofibroma and familial adenomatous polyposis has been described in recent years, but this is controversial (17). From the histologic point of view, the most important and distinctive feature is the striking variation in vessel wall thickness (within and between vessels), ranging from a single layer of endothelium to a muscle coat of variable extent and depth (Fig. 3). This variability likely correlates with the hemorrhagic tendency $(18,19)$. Both the nondescript fibroblastic component (which is associated with variably prominent stromal collagen) and the lesional endothelial cells have been shown to express androgen receptors (20).

Dermatofibrosarcoma protuberans arises in the head and neck region in around $5 \%$ of cases, most often affecting young to middle-aged adults with a male predominance. In this context, scalp is by far the most common location, followed by cheek. Interestingly, a plaquelike, diffuse pattern of growth is more common than exophytic nodularity in the head and neck, but otherwise, the histologic appearances are just the same as at other locations.

\section{NEUROECTODERMAL LESIONS}

The nerve sheath neoplasms most often encountered in the head and neck are benign schwannomas (21-23; including the cellular variant; Fig. 4), granular cell tumors of the tongue/oral cavity (often associated with overlying pseudoepitheliomatous hyperplasia in this location), and solitary circumscribed neuromas (also known as palisaded encapsulated neuromas) in the skin of the "muzzle" area (24). Neurofibromas are relatively less frequent but tend to be of the diffuse or plexiform types and most often occur on the face or scalp. Heterotopic glial (nasal glioma) and ectopic meningothelial lesions (ectopic meningothelial hamartoma and cutaneous meningioma) are rare but distinctive lesions, occurring most often in the nasal region and scalp respectively. In this author's experience, malignant peripheral nerve sheath tumor (MPNST) is perhaps the single most common primary fascicular spindle cell sarcoma in the head and neck region, occurs mainly in adults, and shows a predilection for the sinonasal tract. Because schwannomas and cellular schwannomas at that site are distinctively unencapsulated (23) (Fig. 5) an otherwise worrisome pseudomalignant feature, then cytoarchitectural features, such as Antoni A/B zonation and hyaline vessel walls and the extent of S-100 protein immunopositivity, are important in differential diagnosis. It should also be remembered that in any cytologically atypical or malignant spindle cell neoplasm in the sinonasal tract that shows strong and diffuse S-100 reactivity, spindle cell melanoma needs to be excluded, especially because spindle cell and desmoplastic variants of melanoma often show neural-like nuclear morphology. In this regard, use of second-line melanoma markers such as neuron-specific enolase or D5 may also be helpful; HMB45 and Melan-A are generally of less value in melanomas with spindle cell morphology.

\section{VASCULAR LESIONS}

The various types of lobular capillary hemangioma show a relative predilection for the head and neck region, particularly the juvenile/cellular type (also sometimes known as infantile hemangioendothelioma or strawberry nevus), which can be clinically dramatic in young infants but most often re-

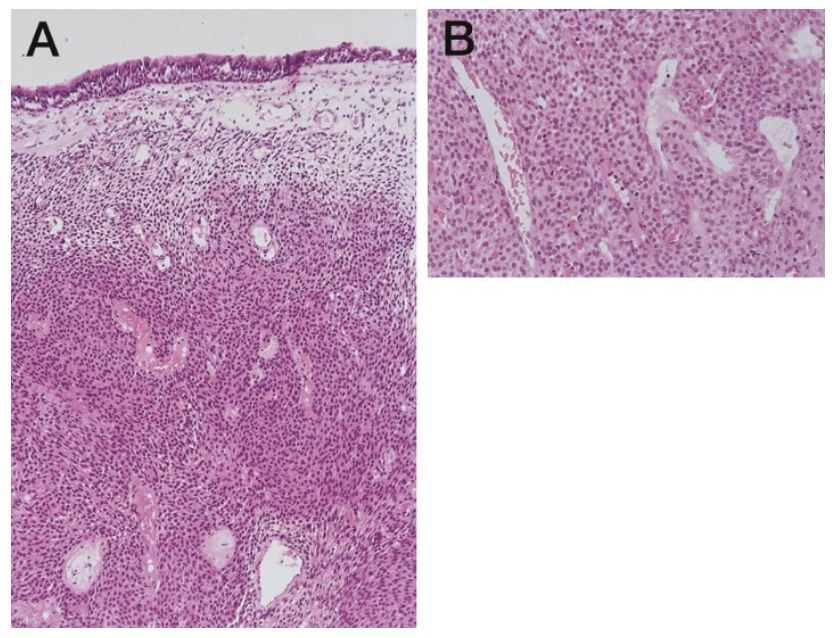

FIGURE 6. Sinonasal hemangiopericytoma. This is a cellular submucosal neoplasm with prominent blood vessels (A). The lesion is composed of relatively monomorphic eosinophilic cells with rather myoid cytomorphology (B). 
gresses spontaneously by the age of 5-7 years (25). Also common is the pyogenic granuloma type, which often affects the oral or nasal mucous membranes (usually in young adults), tends to grow rapidly and bleed, and sometimes recurs locally but nondestructively (26). Tufted angioma is a much more rare cutaneous lesion that tends often to arise on the neck in children or young adults and shows no tendency to regress (27). Epithelioid hemangioma (EH; also sometimes known as angiolymphoid hyperplasia with eosinophilia) occurs most frequently in skin and subcutis of the head (28), particularly around the temple or postauricular region in young to middle-aged adults. Multiple lesions are quite common. Histologically, EH is often associated with a small artery or arteriovenous shunt, and full-thickness transmural involvement of the vessel wall (giving the impression of a blow-out) is common. A lobular growth pattern is only variably evident, and a lymphocytic or eosinophil infiltrate is sometimes prominent. Local recurrence is rare.

Sinonasal hemangiopericytoma (or hemangiopericytoma-like tumor; 29-31) is a rare and somewhat enigmatic lesion that, unlike most so-called hemangiopericytomas, may actually be truly pericytic in nature (32). It occurs in the nasal cavity or sinuses (most often ethmoid sinus) of middle-aged adults of either sex and generally forms a relatively small $(<5 \mathrm{~cm})$, often polypoid mass. Around a third of patients develop local recurrence, but this is usually indolent and nondestructive. Isolated cases pursue a malignant (metastasizing) course, but at least some of these lesions had received prior radiation treatment. Histologically, these lesions are composed of relatively monomorphic spindled or ovoid cells with eosinophilic cytoplasm and bland nuclei, thus giving a rather myoid appearance (Fig. 6). Mitoses are generally rare. Tumor cells are arranged around relatively prominent, small, thinwalled blood vessels. Most cases show immunohistochemical positivity for actin. Factor XIIIa and CD34 positivity are also described but are of questionable significance or specificity.

Angiosarcoma of skin shows striking predilection for the head and neck region (typically the scalp or face) and most often affects older adults, particularly males. The management of these characteristically aggressive neoplasms is made especially difficult by the virtual impossibility of obtaining wide (or suitably radical) surgical margins in this anatomic region.

\section{ROUND CELL SARCOMAS}

Other round cell malignant neoplasms in the anatomic region such as neuroendocrine carcinoma, undifferentiated carcinoma (SNUC), and olfactory neuroblastoma are covered in other manuscripts from this USCAP Long Course. However, round cell sarcomas must be mentioned because of the predilection for rhabdomyosarcoma (33-36) to occur at this site, mainly in young children but also in adolescents and young adults. Excluding parameningeal cases (beyond the scope of this overview), the commonest locations for rhabdomyosarcoma in the head and neck area are the orbit and nasopharynx, followed by the sinonasal tract, middle ear, oral cavity, and neck. As at other locations, there is a slight predominance in males, and the peak incidence is in the first 5 years of life. In this juvenile age group, the embryonal variant is most common, whereas in adolescents and young adults, the alveolar variant predominates. Examples of the spindle cell variant also occur in adults in the oral cavity and are not associated with the same good prognosis as in childhood (mainly paratesticular) cases. As elsewhere, the prognosis of alveolar lesions is poorer than that for embryonal tumors and hence, despite the fact that both are usually treated by the same multimodality therapeutic approach, it is important to make this distinction. Because a discohesive alveolar architecture is quite often not evident and because characteristic wreathlike multinucleate cells may be scarce, the cytomorphologic features (particularly cell/nuclear size, which are larger in the alveolar type, and nuclear variability, which is more prominent in the embryonal type) are the key distinguishing parameters (Fig. 7). Cytogenetic analysis is also of considerable help if suitable material is available (37).

Other round cell sarcomas that are encountered, albeit less often, in the head and neck region include Ewing's sarcoma/peripheral primitive neuroectodermal tumor (PNET), mesenchymal chondrosarcoma (more often osseous than extraosseous at this site; 38), and the poorly differentiated (round cell) variant of synovial sarcoma. Immunohistochemistry plays a central role in this differential diagnosis, and by far the most discriminant antigens (in this specific context) are desmin (and myf4/myogenin) in rhabdomyosarcoma; EMA in synovial sarcoma; and the diffuse, strong, membranous pattern of positivity for CD99 in Ewing's sarcoma/PNET. Given the therapeutic (particularly chemotherapeutic) significance of this differential diagnosis, molecular genetic or cytogenetic analysis is sometimes of critical importance in difficult cases.

\section{MISCELLANEOUS LESIONS}

One mesenchymal lesion that is by far most common in the head and neck and that does not fit readily into the categories described above is atyp- 

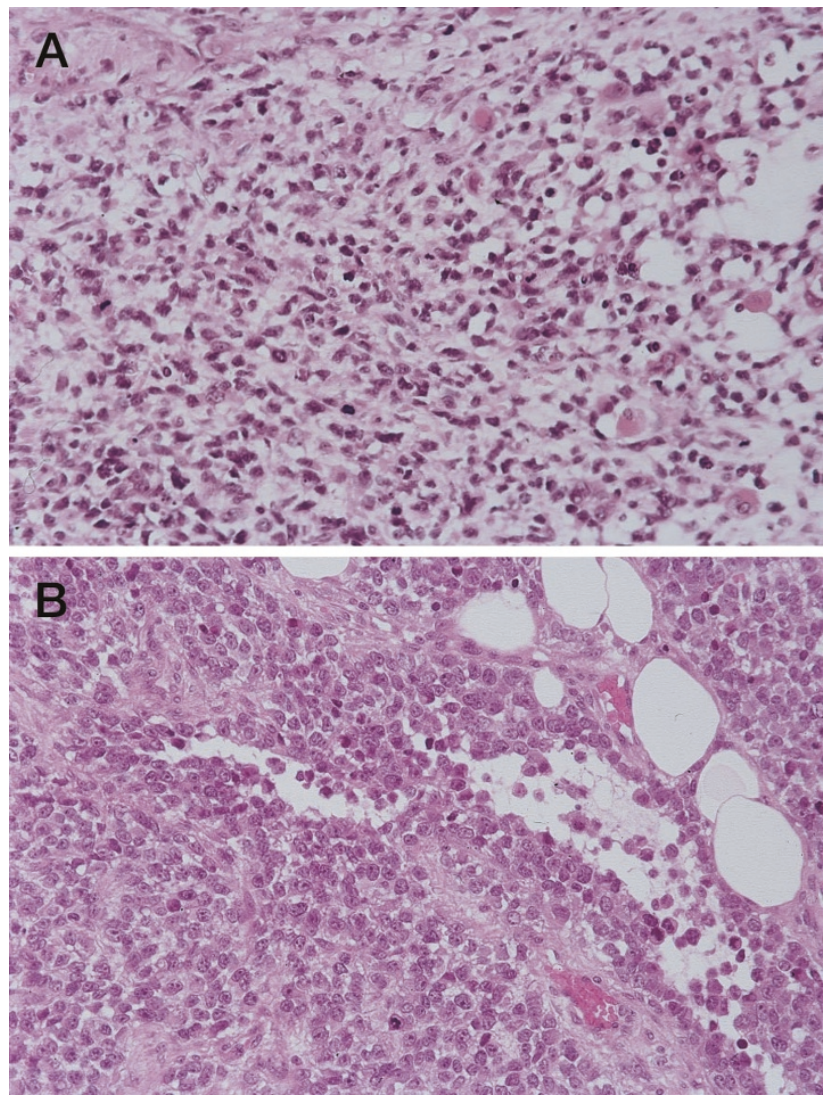

FIGURE 7. Rhabdomyosarcoma. In embryonal lesions (A), note the small nuclear size and pleomorphism, compared with the alveolar subtype (B), in which the nuclei are larger and more uniform in appearance. Both of these sinonasal neoplasms are illustrated at exactly the same magnification.

ical fibroxanthoma. This lesion occurs in actinically damaged skin of older patients, particularly the scalp or ear of males, and is essentially benign if diagnosed by strict criteria. It is an ultravioletinduced pseudosarcomatous proliferation of dermal fibroblasts, often showing very bizarre cytomorphology and abnormal mitoses, that is unassociated with epidermal dysplasia/origin or junctional activity, is virtually confined to the dermis, lacks necrosis or vascular invasion, and is immunohistochemically negative for keratins, S-100 protein, and desmin. Actin positivity of variable extent is a common finding.

Other soft tissue lesions that show a notable tendency to occur in the head and neck region, albeit many of them rare, include spindle cell/pleomorphic lipoma, a relatively common tumor most often affecting older males and arising superficially on the upper back, neck, head, and face; rhabdomyoma (39), which tends to arise in the neck or oropharynx and has both adult and fetal forms; ossifying fibromyxoid tumor (40), which occurs in subcutis of the neck and face; synovial sarcoma (41), which may arise primarily in the neck, sinonasal tract and oral cavity; and alveolar soft part sar- coma, a subset of which occurs in the orbit or oral cavity, particularly in younger females (42).

\section{CONCLUSION}

A wide variety of soft tissue neoplasms may be encountered in the head and neck region, but none are especially common. Because clinical concern for malignancy is often especially high and because some of the lesions in this anatomic region have a tendency to exhibit pseudosarcomatous morphologic features (especially in small or crushed biopsies!), pathologists must always take particular care before rendering a final diagnosis-especially because a diagnosis of malignancy may result in radical and disfiguring treatment. Perhaps the most important rule of thumb is to remember that cytologically malignant spindle cell neoplasms, at least in the adult head and neck, are more likely to represent sarcomatoid examples of squamous cell carcinoma or melanoma than true sarcoma.

\section{REFERENCES}

1. Renshaw AA, Rosai J. Benign atypical vascular lesions of the lip. A study of 12 cases. Am J Surg Pathol 1993;17:557-65.

2. Wanebo HJ, Koness RF, MacFarlane JK, et al. Head and neck sarcoma: report of the Head and Neck Sarcoma Registry. Head Neck 1992;14:1-7.

3. Balm AJM, Coevorden FV, Bos KE, et al. Report of a symposium on diagnosis and treatment of adult soft tissue sarcomas in the head and neck. Eur J Surg Oncol 1995;21:287-9.

4. Lyos AT, Goepfert H, Luna MA, et al. Soft tissue sarcoma of the head and neck in children and adolescents. Cancer 1996; 77:193-200.

5. Wenig BM, Weiss SW, Gnepp DR. Laryngeal and hypopharyngeal liposarcoma. A clinicopathologic study of 10 cases with a comparison to soft-tissue counterparts. Am J Surg Pathol 1990;14:134-41.

6. Golledge J, Fisher C, Rhys-Evans PH. Head and neck liposarcoma. Cancer 1995;76:1051-8.

7. Lauer DH, Enzinger FM. Cranial fasciitis of childhood. Cancer 1980;45:401-6.

8. Sarangarajan R, Dehner LP. Cranial and extracranial fasciitis of childhood: a clinicopathologic and immunohistochemical study. Hum Pathol 1999;30:87-92.

9. Coffin CM, Dehner LP. Fibroblastic-myofibroblastic tumors in children and adolescents: a clinicopathologic study of 108 examples in 103 patients. Pediatr Pathol 1991;11:559-88.

10. Ayala AG, Ro JY, Goepfert H, et al. Desmoid fibromatosis: a clinicopathologic study of 25 children. Semin Diagn Pathol 1986;3:138-50.

11. Coffin CM, Humphrey PA, Dehner LP. Extrapulmonary inflammatory myofibroblastic tumor: a clinical and pathological survey. Semin Diagn Pathol 1998;15:85-101.

12. Chan JK. Solitary fibrous tumour-everywhere and a diagnosis in vogue. Histopathology 1997;31:568-76.

13. Nascimento AG. Solitary fibrous tumour: a ubiquitous neoplasm of mesenchymal differentiation. Adv Anat Pathol 1996;3:388-95.

14. Vallat-Decouvelaere AY, Dry SM, Fletcher CDM. Atypical and malignant solitary fibrous tumors in extrathoracic loca- 
tions: evidence of their comparability to intra-thoracic tumors. Am J Surg Pathol 1998;22:1501-11.

15. Bremer JW, Neel HB, DeSanto LW, Jones GC. Angiofibroma: treatment trends in 150 patients during 40 years. Laryngoscope 1986;96:1321-9.

16. Herman P, Lot G, Chapot R, et al. Long-term follow-up of juvenile nasopharyngeal angiofibromas: analysis of recurrences. Laryngoscope 1999;109:140-7.

17. Guertl B, Beham A, Zechner R, Stammberger H, Hoefler G. Nasopharyngeal angiofibroma: an APC-gene associated tumor? Hum Pathol 2000;31:1411-3.

18. Beham A, Fletcher CDM, Kainz J, et al. Nasopharyngeal angiofibroma: an immunohistochemical study of 32 cases. Virchows Arch A 1993;423:281-5.

19. Beham A., Beham-Schmid C, Regauer S, et al. Nasopharyngeal angiofibroma: true neoplasm or vascular malformation? Adv Anat Pathol 2000;7:36-46.

20. Hwang HC, Mills SE, Patterson K, Gown AM. Expression of androgen receptors in nasopharyngeal angiofibroma: an immunohistochemical study of 24 cases. Mod Pathol 1998;11: 1122-6.

21. Stout AP. The peripheral manifestations of the specific nerve sheath tumor (neurilemoma). Am J Cancer 1935;24:751-6.

22. Bruner JM. Peripheral nerve sheath tumors of the head and neck. Semin Diagn Pathol 1987;4:136-49.

23. Fletcher CDM. Solitary circumscribed neuroma of the skin (so-called palisaded encapsulated neuroma). A clinicopathologic and immunohistochemical study. Am J Surg Pathol 1989;13:574-80.

24. Hasegawa SL, Mentzel T, Fletcher CDM. Schwannomas of the sinonasal tract and nasopharynx. Mod Pathol 1997;10:777-84.

25. Coffin CM, Dehner LP. Vascular tumors in children and adolescents: a clinicopathologic study of 228 tumors in 222 patients. Pathol Annu 1993;28(1):97-120.

26. Mills SE, Cooper PH, Fechner RE. Lobular capillary hemangioma. The underlying lesion of pyogenic granuloma. A study of 73 cases from the oral and nasal mucous membranes. Am J Surg Pathol 1980;4:471-9.

27. Jones EW, Orkin M. Tufted angioma (angioblastoma). A benign progressive angioma, not to be confused with Kaposi's sarcoma or low grade angiosarcoma. J Am Acad Dermatol 1989;20:214-25.
28. Fetsch JF, Weiss SW. Observations concerning the pathogenesis of epithelioid hemangioma (angiolymphoid hyperplasia). Mod Pathol 1991;4:449-55.

29. Compagno J, Hyams V. Hemangiopericytoma-like intranasal tumors. A clinicopathologic study of 23 cases. Am J Clin Pathol 1976;66:672-83.

30. Eichhorn JH, Dickersin GR, Bhan AK, et al. Sinonasal hemangiopericytoma. A reassessment with electron microscopy, immunohistochemistry and long term follow up. Am J Surg Pathol 1990;14:856-66.

31. El-Naggar AK, Batsakis JG, Garcia GM, et al. Sinonasal hemangiopericytomas. A clinicopathologic and DNA content study. Arch Otolaryngol Head Neck Surg 1992;118:134-7.

32. Fletcher CDM. Haemangiopericytoma-a dying breed? Reappraisal of an "entity." Curr Diagn Pathol 1994;1:19-23.

33. Maurer HM, Beltangady M, Gehan EA, et al. The Intergroup Rhabdomyosarcoma Study I. A final report. Cancer 1988;61: 209-20.

34. Qualman SJ, Coffin CM, Newton WA, et al. Intergroup Rhabdomyosarcoma Study - update for pathologists. Pediatr Dev Pathol 1998;1:550-61.

35. Wiener ES. Head and neck rhabdomyosarcoma. Semin Pediatr Surg 1994;3:203-6.

36. Kraus DH, Saenz NC, Gollamudi S, et al. Pediatric rhabdomyosarcoma of the head and neck. Am J Surg 1997;174:556-60.

37. Anderson J, Gordon A, Pritchard-Jones K, et al. Genes, chromosomes and rhabdomyosarcoma. Genes Chromosom Cancer 1999;26:275-85.

38. Nakashima Y, Unni KK, Shives TC, et al. Mesenchymal chondrosarcoma of bone and soft tissue. A review of 111 cases. Cancer 1986;57:2444-53.

39. Willis J, Abdul-Karim F, di Sant'Agnese PA. Extracardiac rhabdomyomas. Semin Diagn Pathol 1994;11:15-25.

40. Williams SB, Ellis GL, Meis JM, Heffner DK. Ossifying fibromyxoid tumor of soft parts of the head and neck: a clinicopathological and immunohistochemical study of nine cases. J Laryngeal Otol 1993;107:75-80.

41. Fisher C. Synovial sarcoma. Ann Diagn Pathol 1998;2:401-21.

42. Simmons WB, Haggerty HS, Ngan B, Anonsen CK. Alveolar soft part sarcoma of the head and neck. A disease of children and young adults. Int J Pediatr Otorhinolaryngol 1989;17: 139-53. 